\title{
Betting, Forex Trading, and Fantasy Gaming Sponsorships-a Responsible Marketing Inquiry into the 'Gamblification' of English Football
}

\author{
Hibai Lopez-Gonzalez ${ }^{1,2}$ (D) Mark D. Griffiths ${ }^{1}$
}

Published online: 25 July 2017

(C) The Author(s) 2017. This article is an open access publication

\begin{abstract}
Environmental stimuli in the form of marketing inducements to gamble money on sports have increased in recent years. The purpose of the present paper is to tackle the extended definition of the gamblification of sport using sponsorship and partnership deals of gambling, forex trading, and fantasy gaming as a proxy for assessing its environmental impact. Using data about sponsorship deals from English Football Premier League, the paper builds on the evidence of English football's gamblification process to discuss the impact that the volume, penetration, and marketing strategies of sports betting might have on public health and wellbeing. Findings demonstrate that gambling marketing has become firmly embedded in the financial practices of many Premiership football clubs. It is argued that such associations are not trivial, and that the symbolic linkage of sport and newer gambling forms can become an issue of public health, especially affecting vulnerable groups such as minors and problem gamblers. The present study is the first to explore in-depth the relationship and potential consequences and psychosocial impacts of sports-related marketing, particularly in relation to football.
\end{abstract}

Keywords Gambling $\cdot$ Sports betting $\cdot$ Marketing $\cdot$ Advertising $\cdot$ Forex trading $\cdot$ Fantasy gaming

Environmental stimuli in the form of marketing inducements to gamble money on sports have increased in recent years (Danson 2010), with numerous social groups and scholars raising concerns about the unknown long-term effects of gambling marketing (e.g. Thomas et al.

Hibai Lopez-Gonzalez

hibai.lopezgonzalez@ntu.ac.uk

Mark D. Griffiths

mark.griffiths@ntu.ac.uk

1 International Gaming Research Unit, Psychology Division, Nottingham Trent University, 50

Shakespeare Street, Nottingham NG1 4FQ, UK

2 Psychology Department, University of Deusto, Bilbao, Spain 
2012a; Yani-de-Soriano et al. 2012). Although accounts of bookmakers directly influencing the formal codification of the laws of sport date back to the 18th century (Forrest and Simmons 2003), there is a growing consensus that a sizeable part of the world today is witnessing an unprecedented proliferation of gambling products focusing on the outcomes of sports competitions (Dyall et al. 2009; Hing 2014; LaPlante et al. 2008; McKelvey 2004; Sproston et al. 2015). Such proliferation prompted McMullan and Miller (2008). As the -fication suffix implies, gamblification is a process that of expanding the areas of sport susceptible to being gamble upon, which has been further accelerated by the nearly simultaneous legalisation and popularisation of Internet gambling in different jurisdictions (Gainsbury et al. 2012).

In the decade since the gamblification of sport theory was proposed, the term has evolved from its original meaning. Sport gamblification is no longer restricted by the limits of sports betting and sport per se. On the contrary, it has developed multiple interactions with adjacent markets. Aligning with a broader context of technological integration of gambling products, as seen in the convergence of gambling and social gaming (Cassidy 2013; (Griffiths et al. 2014), casino gaming (Gainsbury et al. 2014), and digital media (King et al. 2010), sports betting is also under its own process of integration. Sports betting convergences - most notably with trading markets, such as foreign exchange (forex or FX), poker, and daily fantasy games (Lopez-Gonzalez and Griffiths 2016b) - have been further facilitated by the evolution of big data retrieval from sports events (Hutchins 2016). Such developments in sports data retrieval include traditional visual methods, as well as newer motion-tracking cameras, smart sensors embedded in equipment, wearables, and body response tracking devices (Marr 2015). Sport organisations have capitalised on the convergence dynamic by signing formal financial agreements with gambling firms (Hing et al. 2017; Hing et al. 2014; Lopez-Gonzalez and Tulloch 2015; Sproston et al. 2015), but their involvement with the extended definition of gambling markets, including gambling-like products such as trading markets and fantasy games, remains largely unexplored. The convergence of gambling, trading, and gaming markets calls for such an extended understanding of what constitutes gambling today, particularly in the way gambling harm-minimisation and responsible marketing campaigns are designed.

A major preoccupation regarding gambling intersection with sports has been the marketing of betting as an experience inherently associated with the symbolic culture of sport (Deans et al. 2016, 2017a; Gordon and Chapman 2014; Lamont et al. 2011; Thomas et al. 2015). By emphasising its connections with sports, the marketing and advertising of betting has been theorised to pursue the 'sanitation' of gambling (McMullan and Miller 2008), transferring the health-related symbolic attributes of sport and physical exercise to betting behaviour (Milner et al. 2013). In this regard, and of great concern, is the effect that an excessive volume of betting marketing might have on vulnerable groups such as minors and young adults (Pitt et al. 2016; Thomas et al. 2016), and individuals suffering or recovering from gambling problems (Hing et al. 2015, 2016b). Furthermore, additional issues might arise in the event that these new categories that extend the definition of sports gambling (i.e. trading, other gambling forms such as poker, and fantasy games) seeking to market their products in alignment with (or appropriation of) sports' core values and positive attributes. Early examples of this marketing strategy can be found in the sport stars' endorsement of poker brands such as the footballers Neymar Jr. and Cristiano Ronaldo, and the tennis player Rafael Nadal (Lopez-Gonzalez and Griffiths 2016b).

The present paper tackles the extended definition of the gamblification of sport by using sponsorship and partnership deals of gambling, forex trading, and fantasy gaming as a proxy 
for assessing their environmental impact. Using data from English Football Premier League, the paper builds on the evidence of English football's gamblification process to discuss the impact that the volume, penetration, and marketing strategies of sports betting might have on public health and wellbeing. The study is constructed in the form of a conceptual paper that (i) explores the legal framework and (ii) marketing evolution of gambling in English football, (iii) combining it with new descriptive evidence from sponsorship and partnership deals, to finally (iv) speculate on the detrimental consequences that such marketing might have, based on the existing literature on betting marketing-related harm.

\section{Sports Betting Marketing in the UK}

\section{Legal Framework}

Gambling operators can legally market online and offline products in the UK provided they are licensed to do so by the Gambling Commission, the regulatory body created after the Gambling Act 2005. The gambling industry regards the UK as the most developed gambling regulatory system in Europe (Danson 2010). Some scholars have argued that gambling, despite having been a well-established and culturally sanctioned practice for centuries in Britain (Forrest and Simmons 2003; Schwartz 2006), was presented for the first time to the British public by the Gambling Act as a 'viable and socially acceptable leisure activity' (Parke et al. 2014 , p. 24). However, gambling is still regarded - at least in social and economic terms - as a demerit good, in the same vein as tobacco or alcohol, and therefore subject to above average taxation in an attempt to counterbalance the negative effects of its consumption. Demerit goods are those goods that are widely perceived as 'intrinsically unhealthy, degrading or socially damaging' (McCormick and Stone 2007, p. 162). Such mixed understanding of gambling as a legal, tax-collecting, but at the same time demerit activity transpires in the law in the form of regulatory requirements that some scholars have come to label as hypocritical (Myllymaa 2017).

The responsibility of controlling sports betting marketing and advertising in the UK lies on a multi-node network operating under the Gambling Act 2005 and the Gambling (Licensing and Advertising) Act 2014 (Lopez-Gonzalez and Griffiths 2016a). The Gambling Commission, as noted above, is the regulatory body responsible for issuing licenses and regulating gambling activity. Also, in terms of an advertising activity, gambling marketing is further controlled by the Advertising Standards Authority (ASA), which oversees the application of both the UK Code of Broadcast Advertising, and the UK Code of Non-Broadcast Advertising. Moreover, the Office of Communications (Ofcom) protects British consumers from promotions that could be harmful or offensive. Additionally, the gambling industry complements the existing legal framework with self-regulatory codes.

Generally speaking, the UK Gambling Commission has shown specific concern regarding two aspects of betting marketing: the promotion of the so-called free bets and children's protection. The Gambling Commission stipulates that free bet promotions must include in the advert itself any condition or factor that might affect the bets, such as withdrawal requirements. This follows up on the ASA guidance, in response to an increasing number of complaints by bettors concerning the misleading terms of many gambling products advertised as risk-free or simply free (Committee of Advertising Practice and Broadcast Committee of Advertising Practice 2014). 
Sports betting marketing cannot target minors and, in general, cannot feature in their promotions anyone who is or appears to be under 25 years old (Advertising Standards Authority 2014), although some exceptions apply to betting websites featuring sportspeople after the operators' complaints regarding the prohibition to use the image of the footballer Luis Suárez (24 years old at the time) and the golfer Jordan Spieth (aged 22 years at the time) (Smith 2016). Given the rise of foreign gambling operators following sport sponsorship marketing strategies in British football, the Gambling Commission released a one-page advice note in November 2014 to clarify its position on it. The advice solely focused on child protection, reminding consumers that according to the Gambling Act 2005, 'gambling operators will not allow their logos or other promotional material to appear on any commercial merchandising which is designed for use by children. A clear example of this would be the use of gambling logos on children's football strips' (Gambling Commission 2014).

Sport and gambling organisations materialise their shared interests by signing partnership and sponsorship deals, either at competition level (i.e. leagues), organisational level (teams), and/or individual level (sport stars). On top of the financial return agreed on such deals, some sports have claimed additional compensation from betting firms on the grounds of an alleged 'right to consent to bet' by virtue of which sport events should be considered proprietary content, with an authorship, and therefore subject to copyright protection. In French sport, where this rule has been enforced, sports organisers with fixtures covered by bookmakers received $1.1 \%$ of the bets placed by legal operators in the country from 2010 to 2012 (Autorité de régulation des jeux en ligne [ARJEL] 2013), although a 2014 investigation on the matter appointed by the European Commission found little basis for the application of the right to consent to bet (Asser Institute 2014). However, beyond the legal standpoint, sport competitions have arguably few incentives to pursue legal action and be at odds with gambling industry, considering the lucrative sponsorship and partnership deals that a profitable relationship with betting firms has brought to them. Trading and fantasy gaming partnerships with sports industry have not attracted similar public scrutiny and there is no provision that specifically addresses their use in the context of sports betting marketing and advertising.

\section{Volume}

Marketing and advertising expenditure growth in the UK mirrors that of several European and overseas countries that - since the legalisation of online gambling in early 2010 s - have witnessed a surge of gambling inducements (European Commission 2012). Increased marketing following global online gambling adoption has been visible both in territories with a relatively small gambling culture such as Spain (Dirección General de Ordenación del Juego [DGOJ] 2017 [Directorate General of Gambling Regulation DGOJ]), as well as in wellestablished mature markets like Australia, where online sports betting has become the only gambling form with an expanding customer base over the last decade (Gainsbury et al. 2015).

In 2012, sports betting adverts accounted for approximately $0.3 \%$ of all commercial adverts a British adult saw, with almost half of them (45.2\%) being seen while watching sports. In a 1year period, from 2011 to 2012, betting adverts in the UK rose by $270 \%$. Children aged 10 15 years (who are supposedly protected by not seeing gambling adverts on television before 9 p.m.) were reached 148,000 times throughout 2012, 50 times the volume of 2005, because of the legal loophole that allows betting adverts to be broadcast during televised sporting events (Office of Communications 2013). A journalistic report by Nielsen commissioned by The Guardian newspaper in the UK calculated that betting companies had spent $£ 456$ million on 
British television adverts from 2012 to 2015, with an annual growth of $46 \%$ (Davies 2016). Although the causal link between advertising expenditure and gambling engagement is not easy to establish, industry data provided by the Gambling Commission suggests a parallel evolution (Gambling Commission 2017). For example, when considering the (non-remote) betting gross yield (i.e. the money bookmakers retain after paying out prizes for bets won), the UK betting market had a size of $£ 3029$ million in 2012 , $£ 3198$ million in 2013 , 33176 million in $2014, £ 3276$ in 2015 , and $£ 3406$ million in 2016. This evolution represents a relatively modest $12.5 \%$ rise when compared to the $46 \%$ advertising growth over the same period. However, on top of the non-remote yield, remote (domestic) football betting in 2016 accounted for $£ 619$ million, although no historical data is available to trace back the evolution in remote betting due to new methodological arrangements in data collection (Gambling Commission 2017).

In European sporting leagues as a whole, shirt sponsorships in the top five football markets (i.e. England, Germany, France, Italy, and Spain) grew from only one deal in 2002/03 season to 26 deals in the 2010/11 season (Foley-Train 2014). According to latest free-access data from the European Sponsorship Association reported by Foley-Train, gambling operators ranked seventh of all business sectors for worldwide sport sponsorship deals in 2012 (74 deals), tripling the deals made in 2007 (21 deals). For the UK in particular, industry data from the European Gaming and Betting Association (EGBA) estimates that betting companies in 2015 spent around $€ 80$ million exclusively sponsoring English football (EGBA 2015), almost six times more than the $€ 14$ million of annual average expenditure estimated for the 2009-2014 period (Foley-Train 2014).

\section{Gambling Sponsorship in English Football}

Shirt sponsorship is probably a good proxy to calibrate the volume of gambling marketing in English football. Table 1 shows the shirt sponsor evolution over the past decade (from the 2007/2008 to 2016-2017 seasons). First team shirt sponsorship with gambling companies evolved from four deals in 2008, six deals in 2012, to ten deals in 2017, accounting for half of the 20 English Premier League teams. Clearly, the number of shirt logos owned by gambling brands has evolved rapidly over a relatively short period of time. However, some industry voices have been anticipating a decline in the numbers of shirts being sponsored by gambling firms due to their incapacity to compete with other business sectors (Gillooly 2015), although such a decline has yet to materialise. According to Gillooly, the average gambling sponsorship for an English Premier League club in 2014 was $£ 3.9$ million, well below the $£ 11.2$ million average for any other sponsorship in the league.

In the same vein, it has been noted that most of the football teams with shirts sponsored by gambling companies are among the less powerful in the league, both in terms of economic profitability and sporting success. Indeed, analysing the data from end-of-season table positions demonstrates a bias of gambling companies sponsoring teams towards the lower end of the table. Thus, the four teams (out of 20 in the English Premier League) with gambling logos in 2007/2008 finished the league in 6th, 7th, 11th, and 15th. In 2011-2012, the six teams sponsored by gambling companies finished 10th, 11th, 13th, 16th, 18th, and 20th. In 2016/ 2017 season, the ten teams with gambling sponsors showed an almost perfect inverse correlation between table position and gambling-origin shirt sponsor, finishing 9th, 10th, 11 th, 13th, 14th, 15th, 16th, 17th, 18th, and 20th (with the 19th being a money loan company). This could be interpreted as a nuanced strategy. More specifically, gambling operators might 


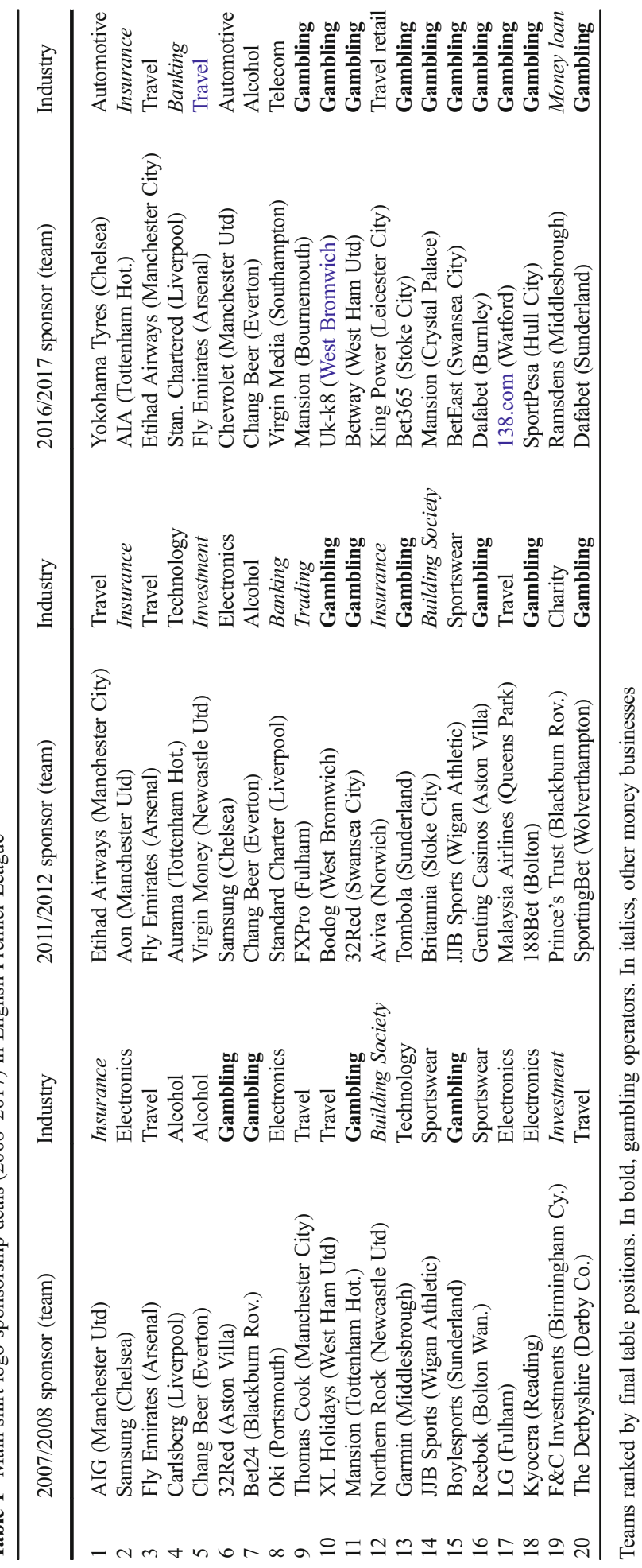


believe they have enough global exposure that the league as whole offers, without needing to pay premium sponsorship deals to attach their brand to the most supported and successful teams (because all the lower ranked teams have to play all the upper ranked teams and therefore get equal advertising exposure during televised games).

Table 2 shows the breadth of the gamblification process by focusing on sponsorship deals during the 2016-2017 season in the English Premier League. As can be observed, all 20 teams have secured at least one official betting partner, with some of them having multiple partners due to regional deals in strategic markets to provide the so-called geo-targeted betting experiences (Garlitos 2014). An illustration example is the Arsenal club's deals with 12Bet company in Asia, Betfair in Europe, SportPesa in Kenya, and Tempobet in Oceania. Altogether, the 20 English Premier League teams totalled 20 different betting brands, with 12 brands sponsoring only one team, five brands sponsoring two teams, and three brands sponsoring three different teams. Despite how fragmented the betting market might look, these brands represent only a small fraction of the actual number operating in association with the English football. In fact, betting brands are generally considered to offer poorly differentiated products in highly competitive markets (Nettleton 2013). Consequently, marketing plays a significant part in artificially creating singular attributes that facilitate the acquisition and maintenance of customers.

Sponsorship deals with trading companies are not as prevalent as betting sponsorships. However, 14 out of 20 English Premier League teams had linked partnership deals with trading companies - most notably forex trading-during the 2016/2017 season. Only one trader

Table 2 Gambling, trading, and fantasy games official partners and sponsors among 2016/2017 English Premier League teams

\begin{tabular}{llll}
\hline Team & Gambling & Trading & Fantasy \\
\hline Arsenal & 12bet, Betfair, SportPesa, TempoBet & Markets.com & DraftKings \\
Bournemouth & Mansion & - & - \\
Burnley & Dafabet & - & Sportito \\
Chelsea & William Hill & CWM FX & - \\
Crystal Palace & Mansion & - & - \\
Everton & William Hill, Dafabet & EZTrader & Football manager \\
Hull City & SportPesa & - & - \\
Leicester City & BetStars, & FairFX & Oulala \\
& 12Bet & & \\
Liverpool & BetVictor & InstaForex & DraftKings \\
Manchester City & Betsafe & iTrader & Ballr \\
Manchester United & Marathonbet & Swissquote & - \\
Middlesbrough & TempoBet, TLC Bet & Ramsdens & - \\
Southampton & SportPesa & Banc De Binary & Premier Punt \\
Stoke City & Bet365 & - & - \\
Sunderland & Dafabet, Betfair & Satsumab & - \\
Swansea City & BetEast, Bet365, Swans Lotto & - & - \\
Tottenham Hotspur & William Hill, Fun88 & EZTrader & - \\
West Bromwich Albion & Coral, Bet365, Uk-k8 & IGOFX & - \\
West Ham United & Betway & eToro & - \\
Watford & 138.com & Divisa & DraftKings, Football manager \\
\hline
\end{tabular}

Partners listed in the English Premier League teams' official websites

${ }^{\text {a }}$ Deal was signed until 2018 but Chelsea discontinued the relationship for undisclosed reasons

${ }^{\mathrm{b}}$ These are quick loan companies per se

${ }^{\mathrm{c}}$ Relationship ended shortly after the onset of 2016/2017 season 
(EZTrader) sponsors two different teams, while the rest are unique sponsors. The same betting market attributes of low product differentiation and competitive environment might also be applicable to trading firms.

Fantasy gaming is rapidly becoming a large component of sports appreciation, especially in the USA where fantasy sports appears to have partially absorbed the consumer base for online sports betting, an illegal activity in most states (Bowman et al. 2016; Rose 2015). Although still in its infancy in Europe, eight out of 20 English Premier League teams already have agreements in place with fantasy sports companies, some of which include a deal with DraftKings, the leading company along with FanDuel in USA's fantasy gaming market. The concentration of brands here is slightly higher than in the case of betting and trading sponsorships, but six different brands still populate the growing fantasy gaming market in the English Premier League.

\section{Exploring the Effects of Sports Gamblification Marketing}

\section{Does Sports Betting Marketing Facilitate Problem Gambling?}

The detrimental effect on public health of an increase in the sports betting marketing volume is difficult to demonstrate. British data collected by the Gambling Commission is inconclusive due to the lack of definition of what constitutes gambling on sports. In general, research has found it difficult to substantiate the causal association between gambling advertising exposure and behaviour, particularly when the effects of such exposure might take place weeks or months later, as proposed, for instance, by the Cultivation Theory (Gerbner 1969). Despite the difficulties of finding empirical evidence of the real impact of marketing on betting behaviour, many authors have acknowledged that the association between marketing and problem gambling is plausible, at least theoretically. In this regard, Binde (2014) concluded after systematically reviewing a large body of gambling advertising literature that it is 'very unlikely that advertising should have no impact whatsoever on problem gambling' (p. 19). However, considering the increasing amount of money allocated to gambling advertising, it appears conceivable that British operators find an attractive return of investment to their advertising expenditure.

The sports betting marketing and advertising growth prompted by the gamblification of sport could be theorised as having two effects. First, an increase in gambling advertising exposure might be associated with a higher prevalence rate of problem gambling. A study indicated that problem gamblers are usually more exposed to advertising (e.g. they frequently visit more gambling websites or watch more sport events); therefore, it cannot be established whether they gamble more because they are more exposed to marketing or they are more exposed to marketing because they gamble more (Hing et al. 2016a). However, a study conducted among 6034 Norwegian gamblers found that problem gamblers had a greater involvement with gambling advertising even when they were similarly exposed than regular non-problem gamblers (Hanss et al. 2015). It is worth noting that available data from the UK shows no indication that gambling advertising has led to more gambling harm. For the period of greatest gambling advertising growth (2012-2015), the problem gambling prevalence rate in Scotland stayed relatively stable, moving from $0.8 \%$ in 2012 to $0.7 \%$ in 2015 (Gambling Commission 2016). The latest data from England dates back to 2012; therefore, the impact (if any) on public health of online betting adoption due to the rise in gambling advertising is as yet unknown. 
Second, an overall rise in the consumption of gambling products following more aggressive marketing strategies, even while maintaining a stable percentage of people experiencing gambling-related harm, would lead to a rise in absolute numbers of people developing gambling problems (Hansen and Rossow 2012). Simply put, keeping problem gambling rate constant, the more people that bet on sports, the more problem gamblers. This is known as the total consumption model. Some scholars have criticised this model by arguing that sports betting marketing does not necessarily create new consumers, and that it only affects market share, transferring existing bettors from one bookmaker to another (Hing 2014). The gambling operators' awareness of the inherent growth limits of the British market could help to interpret the recent mergers between large gambling firms in the UK as an attempt to minimise the huge costs of an intensive competition prolonged over time. Other scholars support social adaptation models (e.g. Shaffer et al. 2004) that propose that while the detrimental effects of marketing and advertising might be true in the initial stages of the exposure, individuals and societies adapt their attitudes, cognitions, and behaviours in the long term, generating resistance to the exposure, for example, by enhancing the social awareness of the problem, counter-advertising the industry's messages, setting up prevention programmes and treatment units, or simply the novelty of the products wearing off as time goes by.

\section{The Naturalisation Effect}

Departing from the impact that a larger volume of gambling stimuli might have on individuals developing gambling problems (as well considering the complexity of assessing marketing's direct effects), other indirect effects that have an impact at group level can be posited. Some of the most notable aspects of gambling marketing are its ubiquity and penetration. Gamblers have repeatedly described commercial stimuli to bet as being everywhere (Pitt et al. 2016). In this regard, the specific messages or narratives that are conveyed by such stimuli do not appear to be as crucial as the accumulative presence of the stimuli. Although each individual brand emphasises their own singular value to their potential target customers, taken as a whole, the aggregated message is more likely to be interpreted along the lines of 'we are here, we exist'. The corollary of this being the real core marketing message of the betting industry has prompted some scholars to conduct scans to determine the 'environmental impact' that the accumulation of betting stimuli might have on the society as a whole (e.g. Sproston et al. 2015).

Some authors have examined the outreach of specific brands, describing how they structure traditional and social media channels to position their products in every market (Sproston et al. 2015). Other studies have examined the combined gambling impact an individual views during in an individual sport event. In the Australian National Rugby League (NRL) in 2012, a spectator watching a game was targeted an average of 322 times with gambling stimuli (Lindsay et al. 2013). Today, gambling stimuli in sports broadcasts, especially football, include live match commentary, sponsors of the networks with onset promotions, commercial breaks before, after and during half-time, electronic and physical banners around the field, shirt logos, on-screen live odds, as well as projected holograms and augmented reality messaging onto the venue's pitch (Lopez-Gonzalez et al. 2017).

The aggregation of marketing strategies over long periods of time has raised concerns regarding the naturalisation or normalisation of gambling on sports over the long term (Deans et al. 2017a, b; Gainsbury and Russell 2015; Hing et al. 2016a; Lamont et al. 2011; Sproston et al. 2015). The naturalisation effect is especially concerning in the case of children and 
adolescents, but also in the case of young adults, with insufficient historical perspective to compare the current betting context against previous periods where the union of sport and gambling was not so pervasively emphasised by betting marketers. Bettors' data directly extracted from gambling companies in Germany indicates that the average age of regular bettors is becoming lower (Gassmann et al. 2015). In that regard, experiments with children aged 5 to 12 years have demonstrated how prevalent their recognition of betting sponsors in association with sport teams is, to the point of recalling sponsorships that never took place (Bestman et al. 2015). Other forms of gambling have prompted children to think in the past that gambling can be a tool for self-expression and rebelliousness (Korn et al. 2005). If the association between gambling and sport becomes fully naturalised, gambling is likely to integrate among its core components the perceived positive attributes of contemporary sport. Here, the present authors provide a tentative list of some of these components:

(i) The role of those practicing sport is active, their actions being the ones determining the outcome of any game.

(ii) Sport is based on talent. The role of chance is inversely proportional to the amount of skill teams or individuals can achieve.

(iii) Sport is based on preparation and work. It is a practice that can be mastered with sufficient training, self-commitment, and discipline (Milner et al. 2013).

(iv) Experience and knowledge are instrumental to success.

(v) Being merit-based, those who have not succeeded have only themselves to blame, considering the equal opportunities the system allows.

(vi) Sport stars represent the story of successful risk-takers that bet against the odds, given the unlikelihood of becoming a professional player, but prevailed in the end.

(vii) For those who excel at it, sport is a very profitable activity.

(viii) Sport is a manifestation of masculinity and control (Anderson 2009; Whannel 2001).

(ix) Sport is fun and exciting.

(x) Sport is safe, harmless, and promotes healthy behaviours (McMullan and Miller 2008).

The following section explores the potential dangers of the transference of meaning from each sport characteristic listed above into the remit of gambling, trading, and fantasy gaming.

\section{Sporting Attributes in Trading and Gaming}

$(i, i i, i i, i v$, and $v)$ : Online betting marketing represents a shift of focus from the traditional view of weekly football pools as a rather passive gambling form where bettors would typically fill out a column with the expected winners of the fixtures of a Premier League week and then wait until the events unfolded. In stark contrast, contemporary betting marketing highlights the active role of bettors and the way mobile technologies can be used to enhance the control over the betting experience, and implicitly, over the bet outcome itself (Lopez-Gonzalez et al. 2017).

The development of betting interfaces towards more involved experiences featuring more options for bettors to interact with the ongoing bets (e.g. 'cash out') has gamified sports betting (Lopez-Gonzalez et al. 2017). This development might punctuate a transition towards a more comprehensive convergence of betting and gaming businesses. If that occurs, the line between the perceived control over the platforms and interfaces, and the actual control over the bets placed will be blurred in bettors' minds, resulting in less planned betting behaviour. 
The more activated the role of bettors is meaningful in terms of and enhanced 'illusion of control' (Langer 1975) and overconfidence over one's own skills (Svenson 1981). Furthermore, it also brings to life the idea that in sports betting, training, knowledge, experience, and skills separate those who win from those who lose. Betting marketing emphasises the idea that all the relevant data to inform bets is accessible for bettors, either in the form of data, statistics, or media reports. It follows that betting is a rational activity that comprises the analysis of available information that, if done diligently, yields profits. Fantasy gaming is a good example of this. Fantasy sports are legal in the USA, despite the prohibition of online gambling in the country, because companies have been successful (to date) in arguing at court cases that their products are based on acts of skill, not chance (Rose 2015). Similarly, trading is also based on the assumption that the chance component can be mastered with enough training and experience. Marketing campaigns overestimate the role of skill (while underestimating the importance of luck), encouraging gamblers to persevere in their skill acquisition. This is relevant in the case of children, because their cognitive skills are still developing, and problem gamblers, who often have distortions and biases in their cognitive processing (Ciccarelli et al. 2017; Griffiths 1994; Parke and Griffiths 2012).

(vi, vii, and viii): Conceptually speaking, one of the characteristics that distinguishes a trader from a gambler is professionalism. Being a trader is perceived to be a job, and it is defined in the Cambridge Dictionary (2017) as a person who buys or sells company shares or money, whereas in the same dictionary, a gambler is defined as a person who risks money. The juxtaposition of gambling and trading, by means of sport, is likely to transfer some of the connotations of professional, business-oriented task of trading to the gambling realm. This juxtaposition is furthered by sport stars, who also add the business component to something that was primarily meant to be an entertainment.

Trading borrows from sport the attributes of speed, immediacy, precision, and technological innovation, which is why Formula 1 car racing has been an ideal target competition for forex companies (Pearson 2013). The preponderance of those same attributes of speed and precision could also help to explain the selection of Usain Bolt, the eight-time Olympic gold medallist sprinter, as a brand ambassador for the XM Forex company in 2016 (Dudley 2016). The symbolic association of gambling and trading via sports makes gambling depart even further from being considered a game of chance, focusing on the components of skill, knowledge, and analysis.

Trading is likely to be an environment of extreme competition, which translates into greater risk of losing the invested money. However, in contrast to such negative characterisation, trading marketing via sports, frames competition as positive, involving a symbolic understanding of trading that entails elements such as the survival of the fittest, the thrill of taking risks, while curtailing any moral obligations caused by irresponsible trading. In close relation to this, the building up of masculinity has therefore been proposed as a mechanism used by gambling advertising to induce riskier betting behaviour (Thomas et al. 2012b). Arguably, trading also builds on recklessness (positively framed as controlled risk-taking) to construct traders and gamblers to the image of sports stars, borrowing characteristics from them such as instinctive behaviour, decisiveness, and on-the-go decision-making. Recent research in the UK has shown that bookmakers manage greater profit margins when presenting bettors with multiple outcome bets whose risk and winning probability is hard to calculate accurately (Newall 2015, 2017).

In addition, elite football evokes a life of affluence. Sport stars often represent stories of working class people who become millionaires almost overnight, typically in their early $20 \mathrm{~s}$ (Smart 2005). In that sense, sport enacts narratives of easy money and strikes of luck, and an association in the mind of quick money. The contention here is that the extended gambling 
definition proposed in this paper does not happen in isolation, and that the convergence of gambling, gaming, and trading businesses is more likely to evolve in an atmosphere saturated by other inducements to play with money. Looking again at Table 1, gambling and trading shirt sponsors align next to brands that could be similarly construed as money businesses: building societies (Northern Rock, Britannia), investment firms ( $F \& C$ Investments, Virgin Money), insurance companies (AIG, Aviva, Aon, AIA), and a quick loan company (Ramsdens). In total, the number of companies inducing consumers to pay now and expect greater return in the future accounted for seven sponsors in 2007/2008, 11 in 2011/2012, and 12 in 2016/2017, embedding further the overall sensation of sport gamblification.

(ix and $x$ ): As mentioned at the beginning of the present paper, gambling products (and even more so trading products) are widely perceived as demerit goods from an economic standpoint (McCormick and Stone 2007). However, unlike other forms of gambling, sport confers betting the attributes of healthiness, safety, and harmlessness (McMullan and Miller 2008). This association is reinforced inasmuch as sports betting becomes more gamified, symbolically departing from more obscure gambling connotations into areas of social perception characterised by playfulness and entertainment. Playing is (by definition) non-serious and entails a world of reparable consequences, as the betting marketing of free bets and guaranteed money-back offers appear to imply. The gamification of gambling (Owens 2012) adds to the active role of bettors, enhancing their perception of control over the outcome of their bets, with fantasy gaming being a by-product of such evolution.

An interpretation of the marketing rationale for the alliance of forex trading companies with sport organisations is the strategy of transferring ludic components from sports domains to reframe trading as a harmless and entertaining activity. Take as an illustrative example the following inducement made by FX Primus, trading partner of English Premier League football club Manchester City until 2016, as advertised in their website:

[Headline] A fusion of Forex and football. [Text] FX trading and football might have more in common than you think...For those of you who enjoy the EXCITEMENT [capital letters in the original], SUSPENSE and SPEED of the beautiful game, then you have already experienced the THRILL that our traders experience when they make money on a trade (Richardson 2015).

This short inducement summarises many of the points made already in the present paper and exemplifies what irresponsible marketing of trading might look like. First, it relies on the 'trading is like a sport' metaphor, borrowing the component of fun and excitement from it. Second, it presents trading as an activity that has no (negative) consequences, in which people engage just for the sake of fun. Third, it draws on the emotional relationship of fans with their sports and teams to evoke a similar feeling in trading.

\section{Concluding Remarks}

The present paper has argued for an extended definition of sport gamblification, exploring the relatively new phenomena of forex trading and fantasy gaming as an expansion of the remit of sports gambling. Using the English Football Premier League as a case study, the paper examined the potential harm involved in the association of sport with gambling and its adjacent industries (i.e. forex trading, fantasy gaming). There is a wide consensus that sports betting marketing (and advertising) must be regulated, and is the case in most jurisdictions 
including the UK. However, there is no specific protection concerning the marketing of trading and fantasy gaming as a specific product category associated with sports. Here, it has been contended that such association is not trivial, and that the symbolic linkage of sport and these newer gambling forms can become an issue of public health, especially affecting vulnerable groups such as minors and problem gamblers.

The present paper explored shirt sponsorship and official partnerships as a proxy for assessing the volume and penetration of sports gamblification. Although there is no scientific evidence that these marketing agreements are actually having a detrimental effect on the aforementioned vulnerable groups, it has been argued that it makes theoretical sense to think that they might potentially cause harm among some individuals. Consequently, the current online gambling restrictions should expand, in the same vein as the definition of gambling, to protect consumers from irresponsible marketing in general and the inadequate association of sport and gambling in particular.

\section{Compliance with Ethical Standards}

Conflict of Interest Hibai Lopez-Gonzalez declares that he has no conflict of interest. Mark D. Griffiths declares that he has received funding for a number of research projects in the area of gambling education for young people, social responsibility in gambling, and gambling treatment from the Responsibility in Gambling Trust, a charitable body which funds its research program based on donations from the gambling industry. $\mathrm{He}$ also undertakes consultancy for various gaming companies in the area of social responsibility in gambling.

Funding Information This work was supported by the Government of the Basque Country, Spain, under grant reference (Eusko Jaurlaritza, POS_2015_1_0062).

Open Access This article is distributed under the terms of the Creative Commons Attribution 4.0 International License (http://creativecommons.org/licenses/by/4.0/), which permits unrestricted use, distribution, and reproduction in any medium, provided you give appropriate credit to the original author(s) and the source, provide a link to the Creative Commons license, and indicate if changes were made.

\section{References}

Advertising Standards Authority. (2014). Gambling advertising: review of the ASA's application of the UK advertising codes. London: Advertising Standards Authority.

Anderson, E. D. (2009). The maintenance of masculinity among the stakeholders of sport. Sport Management Review, 12(1), 3-14.

Asser Institute. (2014). Study on sports organisers' rights in the European Union. Luxembourg: Publications Office of the European Union.

Autorité de régulation des jeux en ligne [ARJEL]. (2013). Report of the French online gaming regulatory authority on the betting right. Paris: ARJEL.

Bestman, A., Thomas, S. L., Randle, M., \& Thomas, S. D. M. (2015). Children's implicit recall of junk food, alcohol and gambling sponsorship in Australian sport. BMC Public Health, 15, 1022.

Binde, P. (2014). Gambling advertising: a critical research review. London: Responsible Gambling Trust.

Bowman, N. D., Spinda, J. S. W., \& Sanderson, J. (2016). Fantasy sports and the changing sports media industry: media, players, and society. Lanham, Maryland: Lexington Books.

Cambridge Dictionary (2017). Trader. Retrieved May 3, 2017, from http://dictionary.cambridge.org/dictionary/english/trader

Cassidy, R. (2013). Partial convergence: social gaming and real-money gambling. In R. Cassidy, A. Pisac, \& C. Loussouarn (Eds.), Qualitative research on gambling: exploring the production and consumption of risk (pp. 74-91). New York: Routledge.

Ciccarelli, M., Griffiths, M. D., Nigro, G., \& Cosenza, M. (2017). Decision making, cognitive distortions and emotional distress: a comparison between pathological gamblers and healthy controls. Journal of Behavior Therapy and Experimental Psychiatry, 54, 204-210.

Committee of Advertising Practice and Broadcast Committee of Advertising Practice. (2014). Guidance on the rules for gambling advertisements. London: Committee of Advertising Practice and Broadcast Committee of Advertising Practice. 
Danson, A. (2010). Sponsorship by gambling companies in the UK and Europe: the opportunities and challenges. Journal of Sponsorship, 3(2), 194-201.

Davies, R. (2016). Betting firms spent half a billion pounds on TV adverts since 2012. Retrieved January 5, 2017, from: https:/www.theguardian.com/society/2016/jul/15/betting-firms-spent-half-a-billion-pounds-on-tv-adverts-since-2012

Deans, E. G., Thomas, S. L., Daube, M., Derevensky, J., \& Gordon, R. (2016). Creating symbolic cultures of consumption: an analysis of the content of sports wagering advertisements in Australia. BMC Public Health, $16(1), 208$.

Deans, E. G., Thomas, S. L., Daube, M., \& Derevensky, J. (2017a). The role of peer influences on the normalisation of sports wagering: a qualitative study of Australian men. Addiction Research \& Theory, 25, 103-113.

Deans, E. G., Thomas, S. L., Derevensky, J., \& Daube, M. (2017b). The influence of marketing on the sports betting attitudes and consumption behaviours of young men: implications for harm reduction and prevention strategies. Harm Reduction Journal, 14(1), 5. doi:10.1186/s12954-017-0131-8.

Dirección General de Ordenación del Juego [DGOJ]. (2017). Gasto promocional de juego online. Madrid: DGOJ.

Dudley, G. (2016). Usain Bolt becomes XM's official ambassador. Retrieved April 10, 2017, from: http://www. sportspromedia.com/news/usain bolt signs on with xm group

Dyall, L., Tse, S., \& Kingi, A. (2009). Cultural icons and marketing of gambling. International Journal of Mental Health and Addiction, 7, 84-96.

European Betting and Gaming Association [EGBA]. (2015). The economic synergy between sports and sports betting. EGBA News, 19, 1-4.

European Commission. (2012). Towards a comprehensive European framework for online gambling. Brussels: European Commission.

Foley-Train, J. (2014). Sports betting: commercial and integrity issues. Etterbeek: European Gaming and Betting Association.

Forrest, D., \& Simmons, R. (2003). Sport and gambling. Oxford Review of Economic Policy, 19(4), 598-611.

Gainsbury, S., \& Russell, A. (2015). Betting patterns for sports and races: a longitudinal analysis of online wagering in Australia. Journal of Gambling Studies, 31(1), 17-32.

Gainsbury, S., Wood, R., Russell, A., Hing, N., \& Blaszczynski, A. (2012). A digital revolution: comparison of demographic profiles, attitudes and gambling behavior of Internet and non-Internet gamblers. Computers in Human Behavior, 28, 1388-1398.

Gainsbury, S., Hing, N., Delfabbro, P. H., \& King, D. L. (2014). A taxonomy of gambling and casino games via social media and online technologies. International Gambling Studies, 14(2), 196-213.

Gainsbury, S., Russell, A., Hing, N., Wood, R., Lubman, D., \& Blaszczynski, A. (2015). How the Internet is changing gambling: findings from an Australian prevalence survey. Journal of Gambling Studies, 31(1), 1-15.

Gambling Commission. (2014). Sponsorship of British sporting clubs by gambling operators. London: Gambling Commission.

Gambling Commission. (2016). Participation in gambling and rates of problem gambling-Scotland 2015. London: Gambling Commission.

Gambling Commission. (2017). Industry statistics (May 2017). London: Gambling Commission.

Garlitos, K. (2014). Betfair inks sponsorship deal with Liverpool. Retrieved December 2, 2014, from: http://calvinayre.com/2014/11/26/sports/betfair-inks-sponsorship-deal-liverpool/

Gassmann, F., Emrich, E., \& Pierdzioch, C. (2015). Who bets on sports? Some further empirical evidence using German data. International Review for the Sociology of Sport. doi:10.1177/1012690215597650.

Gerbner, G. (1969). Toward "cultural indicators": the analysis of mass mediated public message systems. $A V$ Communication Review, 17(2), 137-148.

Gillooly, L. (2015). Why gambling sponsors could be relegated from the Premier League. Retrieved July 10, 2016, from: http:/www.campaignlive.co.uk/article/1376368/why-gambling-sponsors-relegated-premier-league\#

Gordon, R., \& Chapman, M. (2014). Brand community and sports betting in Australia. Victoria: Victorian Responsible Gambling Foundation.

Griffiths, M. D. (1994). The role of cognitive bias and skill in fruit machine gambling. British Journal of Psychology, 85, 351-369.

Griffiths, M., King, D., \& Delfabbro, P. (2014). The technological convergence of gambling and gaming practices. In D. C. Richard, A. Blaszczynski, \& L. Nower (Eds.), The Wiley-Blackwell handbook of disordered gambling (pp. 327-346). Oxford: John Wiley \& Sons.

Hansen, M. B., \& Rossow, I. M. (2012). Does a reduction in the overall amount of gambling imply a reduction at all levels of gambling? Addiction Research \& Theory, 20(2), 145-152.

Hanss, D., Mentzoni, R. A., Griffiths, M. D., \& Pallesen, S. (2015). The impact of gambling advertising: problem gamblers report stronger impacts on involvement, knowledge, and awareness than recreational gamblers. Psychology of Addictive Behaviors, 29(2), 483-491.

Hing, N. (2014). Sports betting and advertising (AGRC Discussion Paper No. 4). Melbourne: Australian Gambling Research Centre. 
Hing, N., Vitartas, P., \& Lamont, M. (2014). Promotion of gambling and live betting odds during televised sport: influences on gambling participation and problem gambling. Lismore: Centre for Gambling Education and Research.

Hing, N., Lamont, M., Vitartas, P., \& Fink, E. (2015). Sports bettors' responses to sports-embedded gambling promotions: implications for compulsive consumption. Journal of Business Research, 68(0), 2057-2066.

Hing, N., Russell, A. M. T., Vitartas, P., \& Lamont, M. (2016a). Demographic, behavioural and normative risk factors for gambling problems amongst sports bettors. Journal of Gambling Studies, 32(2), 625-641.

Hing, N., Sproston, K., Brook, K., \& Brading, R. (2016b). The structural features of sports and race betting inducements: issues for harm minimisation and consumer protection. Journal of Gambling Studies, 1-20. doi:10.1007/s10899-016-9642-6.

Hing, N., Russell, A. M. T., Lamont, M., \& Vitartas, P. (2017). Bet anywhere, anytime: an analysis of Internet sports bettors' responses to gambling promotions during sports broadcasts by problem gambling severity. Journal of Gambling Studies. doi:10.1007/s10899-017-9671-9.

Hutchins, B. (2016). Tales of the digital sublime: tracing the relationship between big data and professional sport. Convergence: The International Journal of Research into New Media Technologies, 22(5), 494-509.

King, D., Delfabbro, P., \& Griffiths, M. (2010). The convergence of gambling and digital media: implications for gambling in young people. Journal of Gambling Studies, 26(2), 175-187.

Korn, D., Hurson, T., \& Reynolds, J. (2005). Commercial gambling advertising: possible impact on youth knowledge, attitudes, beliefs, and behavioural intentions. Guelph: Ontario Problem Gambling Research Centre.

Lamont, M., Hing, N., \& Gainsbury, S. (2011). Gambling on sport sponsorship: a conceptual framework for research and regulatory review. Sport Management Review, 14(3), 246-257.

Langer, E. (1975). The illusion of control. Journal of Personality and Social Psychology, 32(2), 311-328.

LaPlante, D. A., Schumann, A., LaBrie, R. A., \& Shaffer, H. J. (2008). Population trends in Internet sports gambling. Computers in Human Behavior, 24(5), 2399-2414.

Lindsay, S., Thomas, S., Lewis, S., Westberg, K., Moodie, R., \& Jones, S. (2013). Eat, drink and gamble: marketing messages about "risky" products in an Australian major sporting series. BMC Public Health, 13(1), 719. doi:10.1186/1471-2458-13-719.

Lopez-Gonzalez, H., \& Griffiths, M. D. (2016a). Is European online gambling regulation adequately addressing in-play betting advertising? Gaming Law Review and Economics, 20(6), 495-503.

Lopez-Gonzalez, H., \& Griffiths, M. D. (2016b). Understanding the convergence of online sports betting markets. International Review for the Sociology of Sport. doi:10.1177/1012690216680602.

Lopez-Gonzalez, H., \& Tulloch, C. D. (2015). Enhancing media sport consumption: online gambling in European football. Media International Australia, 155, 130-139.

Lopez-Gonzalez, H., Estévez, A., \& Griffiths, M. D. (2017). Marketing and advertising online sports betting: a problem gambling perspective. Journal of Sport \& Social Issues, 41(3), 256-272.

Marr, B. (2015). Big data: the big formula in sports. Retrieved from: https://www. forbes. com/sites/bernardmarr/2015/03/25/big-data-the-winning-formula-in-sports/\#32ca675034de.

McCormick, B., \& Stone, I. (2007). Economic costs of obesity and the case for government intervention. Obesity Reviews, 8(1), 161-164.

McKelvey, S. M. (2004). The growth in marketing alliances between US professional sport and legalised gambling entities: are we putting sport consumers at risk? Sport Management Review, 7(2), 193-210.

McMullan, J. L., \& Miller, D. (2008). All in! The commercial advertising of offshore gambling on television. Journal of Gambling Issues, 22, 230-251.

Milner, L., Hing, N., Vitartas, P., \& Lamont, M. (2013). Embedded gambling promotion in Australian football broadcasts: an exploratory study. Communication Politics \& Culture, 46, 177-198.

Myllymaa, A. (2017). The political economy of online gambling in the European Union. Helsinki: University of Helsinki Retrieved from https://helda.helsinki.fi/handle/10138/175678.

Nettleton, J. (2013). Live odds and the wild, wild west of gambling advertising! Sydney: Addisons.

Newall, P. W. S. (2015). How bookies make your money. Judgment and Decision making, 10(3), $225-231$.

Newall, P. W. S. (2017). Behavioral complexity of British gambling advertising. Addiction Research \& Theory. doi:10.1080/16066359.2017.1287901.

Office of Communications. (2013). Trends in advertising activity - gambling. London: Ofcom.

Owens, M. D. (2012). It's all in the game: gamification, games, and gambling. Gaming Law Review and Economics, 16(3), 114-118.

Parke, A., \& Griffiths, M. (2012). Beyond illusion of control: an interpretative phenomenological analysis of gambling in the context of information technology. Addiction Research \& Theory, 20(3), 250-260.

Parke, A., Harris, A., Parke, J., Rigbye, J., \& Blaszczynski, A. (2014). Responsible marketing and advertising in gambling: a critical review. Journal of Gambling Business and Economics, 8(3), 21-35.

Pearson, S. (2013). FX trading and sports sponsorship. Retrieved April 4, 2017, from http://www. financemagnates.com/forex/brokers/fx-trading-and-sports-sponsorship/ 
Pitt, H., Thomas, S., Bestman, A., Stoneham, M., \& Daube, M. (2016). It's just everywhere children and parents discuss the marketing of sports betting in Australia. Australian and New Zealand Journal of Public Health, 40. doi:10.1111/1753-6405.12564.

Richardson, A. (2015). Forex trading and sports sponsorship — an ethical dilemma. Retrieved from http://www. financial-spread-betting.com/forex-trading-sports-sponsorships.html

Rose, I. N. (2015). Are daily fantasy sports legal? Gaming Law Review and Economics, 19(5), 346-349.

Schwartz, D. G. (2006). Roll the bones: the history of gambling. New York: Gotham Books.

Shaffer, H. J., LaBrie, R. A., \& LaPlante, D. (2004). Laying the foundation for quantifying regional exposure to social phenomena: considering the case of legalized gambling as a public health toxin. Psychology of Addictive Behaviors, 18(1), 40-48.

Smart, B. (2005). The sport star: modern sport and the cultural economy of sporting celebrity. Thousand Oaks, CA: Sage.

Smith, D. (2016). How the Advertising Standards Authority restricts the use of U-25 sports stars in gambling adverts. Retrieved April 5, 2017, from: https:/www.lawinsport.com/articles/item/how-the-advertisingstandards-authority-restricts-the-use-of-u-25-sports-stars-in-gambling-adverts

Sproston, K., Hanley, C., Brook, K., Hing, N., \& Gainsbury, S. (2015). Marketing of sports betting and racing. Melbourne: Gambling Research Australia.

Svenson, O. (1981). Are we all less risky and more skillful than our fellow drivers? Acta Psychologica, 47(2), $143-148$.

Thomas, S., Lewis, S., Duong, J., \& McLeod, C. (2012a). Sports betting marketing during sporting events: a stadium and broadcast census of Australian Football League matches. Australian and New Zealand Journal of Public Health, 36(2), 145-152.

Thomas, S., Lewis, S., McLeod, C., \& Haycock, J. (2012b). "They are working every angle": a qualitative study of Australian adults' attitudes towards, and interactions with, gambling industry marketing strategies. International Gambling Studies, 12(1), 111-127.

Thomas, S., Bestman, A., Pitt, H., Deans, E., Randle, M., Stoneham, M., \& Daube, M. (2015). The marketing of wagering on social media: an analysis of promotional content on YouTube, Twitter and Facebook. Victoria: Victorian Responsible Gambling Foundation.

Thomas, S., Pitt, H., Bestman, A., Randle, M., \& Daube, M. (2016). Child and parent recall of gambling sponsorship in Australian sport. Victoria: Victorian Responsible Gambling Foundation.

Whannel, G. (2001). Media sport stars: masculinities and moralities. London: Routledge.

Yani-de-Soriano, M., Javed, U., \& Yousafzai, S. (2012). Can an industry be socially responsible if its products harm consumers? The case of online gambling. Journal of Business Ethics, 110, 481-497. 